\title{
Educação em tempos de mercantilização
}

\begin{abstract}
Resumo: em tempos de mercantilização na educação, acima de tudo, ela sofre as consequências, mas, também tem poder de intervenção social. Deste ponto de vista procura-se trazer reflexões acerca do momento atual em que estamos vivenciando na área educacional, admitindo crises da educação e da sociedade. Este ensaio é baseado em estudos teóricos e a partir dele arrisca-se fazer proposições a partir do potencial de mobilização das pessoas que se envolvem e atuam no sentido de buscar transformações. Fala-se do papel do Estado frente a sua função e se evidencia as contradições deste, quando de um lado, assume a educação como dever e, de outro, privilegia instituições privadas de ensino bem como outras empresas do setor econômico em detrimento da educação pública.

Palavras chave: Educação escolar pública. Mercantilização do ensino.
\end{abstract}

\section{Introdução}

Em muitos lugares, desde o âmbito privado, na rua, em bares, além de escolas e demais instituições direta ou indiretamente ligadas a processos educacionais, a grande maioria das pessoas falam e formam opiniões acerca da educação. Diante disso, talvez se possa arriscar afirmar que esta é uma das áreas em que, independente de conhecer e estudar sobre o assunto, todos palpitam. Desta forma, fica explícito que não são poucos os debates sobre o tema, e por outro lado, é bastante nítido o senso comum, reforçado por alguns especialistas, de que a educação (especialmente a de caráter público) no Brasil não anda bem, além de que, o problema se arrasta há muito tempo. Acerca disso, nos propomos a elucidar algumas questões.

O referido texto é baseado em estudos bibliográficos e busca somar-se à continuidade nas reflexões a respeito do difícil contexto que vivemos com relação à educação na sociedade de economia globalizada pelo capital, conforme diria Mészáros (2005). Num primeiro momento nos parece fundamental, então, esclarecer que falamos em mercantilização devido ao fato de que

No reino do capital, a educação é, ela mesma, uma mercadoria. Daí a crise do sistema público de ensino, pressionado pelas demandas do capital e pelo esmagamento dos cortes de recursos dos orçamentos públicos. Talvez nada exemplifique melhor o universo instaurado pelo neoliberalismo, em que 'tudo se vende, tudo se compra', 'tudo tem preço', do que a mercantilização da educação. (SADER, 2005, p. 1)
Isaura Isabel Conte

Universidade Regional do Noroeste do Estado do Rio Grande do Sul isauraconte@yahoo.com.br 
Contudo, pode-se perceber a complexidade que envolve a educação, pois, acima de tudo ela faz parte e é diretamente influenciada pelo habitus social, segundo Bourdieu (1989). Logo, não se trata de autonomia do sistema educacional, e sim de interrelação, com a sociedade. Contudo, há de se ter cuidado com análises pessimistas e deterministas, senão fatalistas, quando se faz tal consideração, pois a sociedade, notoriamente apresenta-se com profundas desigualdades, de classe, raça/etnia, gênero etc. De outra maneira, porém, não poderíamos deixar de mencionar que muitos avanços no campo sociocultural das últimas décadas foi possível devido à contribuição da educação, nas suas mais variadas formas de produção e reprodução do conhecimento. Desse modo, assim como é reproduzido, de ser também modificado na e por meio da própria educação.

Assim, temos a relação intrínseca entre educação e sociedade, e Mészáros (2005, p. 25) afirma que

\footnotetext{
Poucos negariam hoje que os processos educacionais e os processos sociais mais abrangentes de reprodução estão intimamente ligados. Consequentemente, uma reformulação significativa da educação é inconcebível sem a correspondente transformação do quadro social no qual as práticas educacionais da sociedade devem cumprir as suas vitais e historicamente importantes funções de mudanças.
}

De acordo com o mesmo autor, o fracasso de esforços anteriores no sentido de apostar que a educação faria grandes transformações na sociedade, reconciliadas com o avanço do capital, consistia e ainda consiste no fato de que o sistema do capital é irreformável e incorrigível. Frente a este fato, vale ressaltar que, sempre que forem efetuadas críticas à educação, é importante lembrar que a educação por si só não possui autonomia, conforme já pontuamos. Além disso, uma análise historicizada do processo educacional do país contribui para que não percamos de vista a engenharia social, onde, de forma especial as classes populares foram colocadas á margem e/ou com acesso limitado como se fossem pessoas de segunda categoria.

Sobre este contexto Pereira (1973) auxilia na reflexão, quando aponta em seus estudos que, desde o Brasil colonial a centralização administrativa da metrópole não permitia que a leitura e a escrita fossem sentidas como necessidades do povo e, junto a isto, 
não havia possibilidade de participação política. A autora afirma ainda, que os maiores esforços em vista de construir um sistema educacional, se deram do início do século XIX em diante, pois até aí, a educação como sistema público era praticamente inexistente.

Nesta mesma época, segundo a mesma fonte, tornou-se necessário um sistema de ensino que atendesse a demanda da aristocracia e de seus quadros funcionais, os quais passaram a dirigir o país. De outro modo, com relação à educação das classes populares, foi viabilizado o ensino de primeiro grau para transmissão de conhecimentos indispensáveis a agricultores, comerciantes, operários etc. Mas, desde lá, quando em nome do poder central foi assumido a educação de nível primário, ordens religiosas passaram a oferecer ensino secundário sob pagamento, delimitando, desta forma quem poderia ter acesso a ela.

Como se pode perceber, desde o início de um sistema mais consistente de educação no país, houve estruturação para a manutenção e a consolidação das desigualdades entre as classes sociais. Nesta perspectiva, se criou condições de acesso ao ensino de qualidade a alguns, em detrimento da maioria. Na arguição de Paludo (2001), é evidenciado que no Brasil foram criadas escolas para os ricos diferentemente do nível das escolas para os pobres, onde os primeiros se constituíam em classe dirigente, ao passo que, os pobres aprendiam no necessário para o mundo do trabalho e, aceitação de sua condição. Para complementar, poderíamos mencionar a escola dualista de que fala Saviani (2009) ${ }^{1}$ sendo que nesta, ainda que se encontram os filhos da classe operária, a hegemonia é dada pela classe burguesa. Contudo, Pinto (1986, p. 87) descreve que

Numa sociedade de classes há um processo dominante de educação, que não é outra coisa senão uma forma de dominação de classe, de uma classe sobre as demais... [...] Por outro lado, nas classes dominadas também dá-se, sob formas variadas, um processo educativo, que se caracteriza por uma certa resistência à educação dominante, gerando conhecimentos e valores que lhe são próprios.

Sendo assim, a educação, apesar da conotação elitista e classista é de suma importância para as classes populares, que por sua vez, através dela vai aprendendo a decifrar códigos fundamentais para compreender o mundo e, possivelmente dizer suas palavras. Com relação a este aspecto, Freire (1996, p. 126) diria: "Se a educa-
(1) A teoria da escola dualista, segundo Savaini (2009) foi elaborada por Baudelot e Establet e, apesar da aparência de unitária e unificadora, é dividida entre interesses proletários e burgueses conforme a divisão da sociedade capitalista. 
(2) De programa passa a ser assumido como política pública em 1998, com especificidades do campo, incluindo áreas de assentamentos, acampamentos rurais, população ribeirinha, povos tradicionais entre outros. ção não pode tudo, alguma coisa fundamental ela pode", por isto, mesmo com todas as críticas a respeito do campo educacional não se pode negar sua importância, inclusive frente às possibilidades de contestação da sociedade e de tecer reflexão a si própria.

O acesso à escola por parte das classes populares permitiu e permite os empobrecidos (as), organizados em movimentos populares, conhecer para tecer críticas às políticas de educação, mas, também, fazer exigências em vista de poderem fazer educação a partir de seus contextos e concepções, a partir de alguns programas ou políticas como, a educação do campo por exemplo. Desse modo, se a maneira como o sistema educacional do país foi organizado e vigora, com poucas chances de as pessoas mais empobrecidas poderem permanecer (não culpabililizando a estrutura escolar, somente, mas, considerando a esfera social), de um lado, se são expulsos, de outro, em forma de resistência, em geral em movimentos articulados, uma parcela consegue, não só ter acesso à educação, como forjar outros formatos dela, onde se sintam talvez mais sujeitos.

Com isto não queremos dizer que o sistema educacional juntamente com a sociedade continue evadindo pessoas, pois, nem todas conseguem estar em Organizações, as quais poderiam as levar a lutar pelo acesso a educação. Como enfatiza Ribeiro (2009), na sociedade do conhecimento, não há que se separar o vínculo entre educação e trabalho e, por isso, entendemos que, diante da necessidade básica do ser humano, que precisa trabalhar para se manter vivo, vai optar pelo trabalho (em geral precarizado) em detrimento da educação escolar.

O Estado, que tem assumido a educação até o nível médio como de caráter público e universal, o que é avanço, se comparado há meio século, precisa estar em pauta diante das políticas educacionais e os interesses particulares de grupos empresariais com interesse em lucrar com a educação, afinal, tem responsabilidades para com os cidadãos e cidadãs, que neste caso não deveriam ser considerados clientes, conforme tem ocorrido com a mercantilização.

\section{O contexto da educação pública}

Conforme mencionado anteriormente, por muito tempo no país, a educação não foi de caráter público e, mesmo quando 
assumida como dever do Estado, o índice de analfabetismo, especialmente de mulheres e das classes populares continuava sendo um grande problema. Segundo o Manifesto dos pioneiros de $1932^{3}$ ainda nas décadas de 1920 a 1940, o índice de analfabetos, chegava (3) Ver referências do texto de Azevedo, Fernando (19--). a 65\%, considerando que na época, populações indígenas e quilombolas em sua grande maioria não eram contabilizadas.

De acordo com Pereira (1973), a partir deste período houve intensivas campanhas e "bandeiras" em vista de diminuir significativamente o analfabetismo. Constata-se, entretanto, que as autoridades, especialmente, o tinham como um grande mal, como "cancro do país" e, devido a isto se falava em erradicação e combate, como se fosse uma doença contagiosa. Acreditava-se que, diminuindo o analfabetismo (basicamente possibilitando algum nível de leitura e escrita) o país iria dar um grande salto em termos econômicos e sociais.

Neste aspecto, o sociólogo Florestan Fernandes, em tom de denúncia, enfatizava que o Brasil bem como o sistema educacional era pensado de fora para dentro, sob força da burguesia dependente, colonialista e também colonizada por burguesias estrangeiras. Contudo, ele não deixava de lutar a favor da educação pública, mesmo se juntando aos liberais, ao passo que, por outro lado, tecia duras críticas a estes, pelo fato de não perceberem que para transformar as instituições seria necessário alterar outras dimensões da sociedade, ou seja: Florestan defendia que, para além das reformas educacionais, o país necessitava de um processo revolucionário para sair da dependência de burguesias nacionais subordinadas, segundo Fávero (2005).

Dados atuais sobre a educação do país apontam uma realidade em que se tem avançado significativamente nos últimos 15 anos, no entanto,

Para se ter uma ideia, 97,6\% das crianças e adolescentes entre 7 e 14 anos estão matriculados na escola, o que representa cerca de 26 milhões de estudantes. Esses 2,4\% podem parecer pouco, mas representam 680 mil crianças fora da escola. É mais do que a população do Suriname. E desse total de crianças fora da escola, 66\% (450 mil) são negras. Da mesma forma, o percentual de crianças fora da escola na Região Norte é duas vezes maior do que o mesmo percentual na Região Sudeste. [...] Enquanto a população urbana possui, em média, 8,5 anos de estudo concluídos com sucesso, a rural tem apenas 4,5. Em relação à população branca, os negros possuem, em média, 
(4) Cita-se o bolsa família e bolsa escola de forma específica. dois anos de estudo a menos. A população nordestina acima de 15 anos é a menos escolarizada do País. Essa parcela da população possui apenas seis anos de escolaridade, enquanto a média nacional é de 7,3 anos.[...] Do total de crianças com 10 anos de idade no Nordeste, 12,8\% não sabem ler. A média nacional é de 5,5\%. Já no Sul o indicador é de 1,2\%. Embora importantes conquistas tenham sido obtidas nos últimos 15 anos, os Estados da Amazônia Legal Brasileira ainda têm mais de 90 mil adolescentes analfabetos e cerca de 160 mil meninos e meninas entre 7 e 14 anos fora da escola. (UNICEF, 2010)

Não deixando de considerar os progressos educacionais do país, como já mencionado e, olhando para os dados anteriormente expostos, seria ingenuidade comentá-los descolados do debate do contexto social, ou mesmo culpabilizando a escola, educadores (as) e dos próprios educandos e educandas pelo analfabetismo, repetência, "evasão" escolar, não aprendizado etc. Conforme Ceccon e Oliveira (1996), em geral, é isto que acontece: os professores veem o fracasso escolar como culpa dos alunos ao passo que os pais, ou concordam com este fator, ou, atribuem simplesmente, a responsabilidade aos educadores e educadoras.

Vivemos numa sociedade de desigualdades entre as classes, na qual a distância entre o universo dos ricos para com os empobrecidos tem sido cada vez maior, apesar de algumas políticas assistenciais, as quais perpassam a educação ${ }^{4}$ entretanto, a educação é assumida como direito de todos e dever do Estado e a contradição disso é que, o caráter público deixa de existir quando um número significativo de educandos(as) em idade escolar possui o direito ao acesso à escola (preferencialmente pública), mas não consegue permanecer nela.

Diante deste aspecto, com relação às comunidades mais empobrecidas, um fator relevante a ser considerado na chamada "evasão" ou expulsão escolar, é a falta de condições mínimas, desde vestuário, água potável e acesso a eletricidade e a própria violência que impõe medo de as pessoas circularem livremente. Quando há evasão, ou melhor, quando por vários motivos são evadidos da escola, é comum ouvir dizer que "eles (as) não demonstravam interesse, etc., ao passo que, a análise do que leva a este fator, é pouco considerada ou sequer percebida". Por parte da escola, geralmente se fazem certas cobranças generalizadas em vista do convívio coletivo e, diante disso, muitas vezes, não é levado em conta que as 
crianças, adolescentes ou jovens que frequentam a mesma escola estão em situações completamente diferentes, senão adversas.

Desta forma, a exclusão vai sendo forçada por mecanismos que nem as educadoras e os educadores percebem na maioria das vezes, sendo que o fazem em nome da igualdade numa sociedade onde ela não existe. Não se trata de culpabilizar os profissionais, pois, a eles é cobrado que devem possibilitar um ambiente onde se possa fazer acontecer aquilo que é tarefa da educação pública. Portanto, algumas questões fogem de suas alçadas, não podendo eles e elas, resolver problemas de ordem estrutural na sociedade de classes.

Neste sentido, as reflexões levantadas ou as problemáticas trazidas, de um lado não podem eximir educadores(as) de sua tarefa de educar e humanizar (ARROYO, 2000) mesmo diante de adversidades e do caráter público da educação e, de outro, a humanização poderá acontecer se houverem mudanças significativas no que tange à sociedade e o jeito de pensar o sistema educacional e sua função.

Pensar a função da educação como parte de mudanças estruturais em tempos de mercantilização, se constitui em uma tarefa árdua, porém imprescindível se quisermos parar de fazer de conta que a educação é de fato importante e cumpre um papel relevante em vista de transformações. Percebe-se que algumas responsabilidades são atribuídas aos educadores (as) ao passo que decisões fundamentais são tomadas por outras esferas de poder político. Se de um modo, há muito esforço ou, também pouco, por parte de profissionais que estão no cotidiano escolar, de outro, decisões que vêm "de cima", muitas vezes desmantelam e desestimulam aqueles e aquelas que estão engajados(as) na causa educacional.

Constata-se que algumas políticas de repressão por parte do Estado, contra a própria luta efetuada pela categoria dos educadores(as), é um dos exemplos de arbitrariedade, afora, cortes em planos de carreiras, currículos impostos a partir de interesses meramente empresariais e até mesmo a formação de profissionais feita com a finalidade de "maquiar" os números da educação para apresentar ao Fundo Monetário Internacional (FMI).

Laval (2004) destaca que da década de 1970 em diante e, mais fortemente na década de 1980 no Brasil, o liberalismo impôs a chamada pedagogia da gestão, em que os professores são como gerentes de suas classes e, de pessoas humanas são transformados em recursos humanos, a favor do mercado e, nesta lógica 
(5) Bertolin (2009) descreve a privatização moderada, sendo aquela em que a oferta é pública com recuperação parcial dos custos através do financiamento privado. A pseudoprivatização é descrita como aquela em que o setor privado é gerido de forma privada, mas com financiamento público. aproxima-se escolas de empresas. Neste mesmo sentido, fala-se em gerencialismo da educação, e, trata-se de uma ideologia que se difunde no campo educacional disseminando princípios orientados pela eficiência financeira. (SHIROMA, 2003) Assim, a privatização, ou seja, a interferência privada na educação pública recebe forte incidência, seja de forma moderada ou pseudoprivatização ${ }^{5}$ no dizer de Bertolin (2009).

De acordo com Streck (2002), do ponto de vista do dilema entre o bem comum e a mercadoria se percebe interesses acima de tudo econômicos na administração e na produção de produtos para a educação, desde livros a softwares educativos. Segundo o mesmo autor, por mais que a privatização e a mercantilização seja percebida mais nitidamente no ensino superior, elas perpassam todos os níveis de educação e a estimativa é que de 2010 em diante haja mais universidades empresariais do que as tradicionais baseadas em campi. No caso da América Latina, muitos países se encontram na situação de terem mais cursos de doutorado oferecidos por universidades espanholas do que por universidades nacionais. Neste quadro de globalização, o mercado se constitui o critério de uma nova ordem institucional.

Tentando colocar um questionamento sobre o quadro apresentado por Streck, podemos rebuscar o que Freire (1996) já havia argumentado sobre a educação como possibilidade de formar sujeitos. Ele falava a partir dos esfarrapados e esfarrapadas do mundo, defendendo que "[...] a liberdade de comércio não pode estar acima da liberdade do ser humano". (FREIRE, 1996, p. 147) Para complementar, Milton Santos (2001), propunha a necessidade de mudança desde "os de baixo" que se mobilizam para forjar transformações, contudo, esses sujeitos necessitam de no mínimo estarem em condições de poder ainda almejar mudanças.

Florestan como lutador engajado pela defesa e ampliação da educação pública e de qualidade no país, denunciava o capitalismo dependente enquanto rumo que o país foi tomando e que isto incidia e incide diretamente nos campos econômico, político, cultural, social, e, portanto nos rumos da educação. Para Florestan (apud FÁVERO, 2005, p. 51), "[...] em lugar de uma política de desenvolvimento econômico, contamos com uma política de expansão de setores privilegiados da produção". Partindo deste ponto de vista, verifica-se que se tem muito o que fazer para que as escolas e a educação, apesar da mercantilização, da interferência de setores 
empresariais e, porque não, organismos internacionais como Banco Mundial, Organização Mundial do Comércio e FMI, consigam fazer algo no sentido de contrapor a dependência e os privilégios de poucos em detrimento da educação de qualidade e da vida de muitas pessoas.

\section{Tentando encontrar possíveis saídas}

Diante de um histórico um tanto pessimista da educação, do ponto de vista da classe explorada e empobrecida, uma das possíveis convicções é acreditar que nada ou quase na vele a pena. A outra, em sentido contrário, impulsiona para acreditar que é possível fazer diferente e não cair no pessimismo enfadonho. Pode-se dizer que esta última é uma concepção freireana, uma vez que Freire e uma enormidade de pessoas vinculadas à concepção de Educação Popular fomentaram mantêm a esperança em vista das transformações possíveis, sabendo que a sociedade e seus sistemas de educação ou quaisquer outros, são obras dos seres humanos.

Desta forma, acreditar no ser humano como construtor de sua história, desde a possibilidade de ser sujeito já é alguma coisa não desvinculada da educação, pois, se ela foi e continua sendo importante para produzir hegemonia, é possível também a produção da contra-hegemonia (GRAMSCI, 1982) apesar da sociedade estar ancorada em princípios de mercado, como já dizia Streck (2002) baseado em Michel Apple. Neste sentido, basta perceber que a sociedade e as pessoas necessitam, acima de tudo, de princípios humanos que não sejam os do mercado e, que as escolas possam cumprir as funções de escola e não de empresas.

Durante milhares de anos, a humanidade viveu sem a regulamentação mercadológica regida pelo capital e, a partir deste olhar, pode-se possibilitar leituras sobre valores contra-hegemônicos a serem potencializados na educação nos dias atuais, pois, sempre escapa algo da hegemonia, ela não é absoluta justamente pelo fato constituição humana das pessoas. Acima de tudo, quem faz a ciência e o conhecimento são as pessoas e, por isso, há possibilidade de direcioná-los, questioná-los, reinventá-los. Se as escolas, em grande medida estão sob a égide do gerencialismo, em que, os educandos e educandas são tidos como clientes, sendo estimulados à concorrência e, os(as) professores(as) tratados como agentes facilitadores, é mais que tempo de nos perguntarmos, qual é mesmo o sentido e 
a função da educação? E, que sociedade estamos construindo com tal educação, afinal, milhares no mundo todo passam por processos formais em instituições de ensino.

Abordando, especificamente o contexto das escolas públicas, e junto à população empobrecida, se diria a partir de Florestan Fernandes, citado por Fávero (2005), que é uma necessidade fazer com que o povo se reaproprie de seu saber, devido à classe burguesa ter roubado a sua capacidade de pensar. Imagina-se que a luta pela educação, vá então, desde reivindicações pela valorização do trabalho da categoria, perpassando estrutura física das instituições à embates contra políticas neoliberais de mercado, pois: "O objetivo central dos que lutam contra a sociedade mercantil, a alienação e a intolerância é a emancipação humana" (MÉSZÁROS, 2005, p. 15).

Diante da problemática e das dificuldades que envolvem a educação e os sistemas educacionais, muitas vezes para maquiar a realidade, são criados discursos, especialmente por parte de governos e seus planos político-partidários, em que a palavra Progresso vira central. Concretamente em planos educacionais como o "fazer mais com menos" é definitivamente retrocesso e não progresso.

Quando se trata abordagens relacionadas a progressos na área da educação, podem ser feitas ponderações com base em Gramsci, Paulo Freire, Florestan Fernandes, Conceição Paludo, Mônica Molina e tantos outros e outras, a respeito do que significa o progresso e do ponto de vista de quem e, para quem. Neste sentido, o desmantelamento do sistema público de educação brasileira pode muito bem ser visto por empresários que lucram com a educação privada, como sendo algo muito positivo, uma vez que serve a seus interesses particulares de acumulação ao passo que mais e mais pessoas vão sendo excluídas dos sistemas escolares.

\section{Considerações finais}

Cabe aqui fazer algumas considerações acerca do que já foi evidenciado ao longo do texto em que tentamos tratar de algumas problemáticas do que implica estar fazendo parte e pensando a educação nos tempos atuais, compreendendo tempos de globalização ou de mundialização do capital.

Em primeiro lugar, é notório as dificuldades dos sistemas educacionais os quais sofrem pressão do e no contexto da mercan- 
tilização, em que se mercantiliza aquilo que deveria ser um bem público disponível a todos(as) e com qualidade.

Frente a isto, têm-se as instituições empresariais, tidas como melhores e mais qualificadas para formar profissionais de acordo com as normas de grupos empresariais que lucram exorbitantemente. Tais instituições conseguem fazer marketing e convencer, inclusive o próprio governo, o qual destina recursos direta ou indiretamente na forma de abatimentos em impostos, por exemplo. Questiona-se então, o que é proporcionado de incentivos às instituições públicas de ensino e, como se possibilita a formação dos profissionais da rede pública.

Além do fato de a sociedade exercer força para fazer a educação ser o que ela é, há sempre jogos de interesses, onde cabe o interesse do ponto de vista contra-hegemônico. Neste sentido, há espaço para manifestações pela educação pública, preferencialmente, para que o Estado cumpra de fato seu dever. Para isto acontecer um dos caminhos possíveis, é a mobilização a partir de movimentos populares consolidados ou não, uma vez que à burguesia força para conservação sistema continuar como está. Força para que a educação seja cada vez mais, objeto de mercantilização e fonte de lucros em detrimento do bem comum e de algo que deveria ser potencializadora de humanização e emancipação.

Como algo fundamental, pontuamos, que a educação tem uma função que é para o ser mais, no sentido freireano, ou seja, para o omilitaralidade da qual falava Marx, sendo entendida como totalidade do desenvolvimento humano produtivo; capacidade de consumo e prazeres, com gozo dos bens espirituais e materiais, que merecem todas as pessoas, segundo Manacorda (1991), mas que isto seria possível não na sociedade capitalista.

\title{
Education in times of merchantability
}

\begin{abstract}
: in times the merchatability of education, above all, it suffers the consequences, but also has the power of social intervention. From this point of view seeks to bring reflections on the present moment we are experiencing in the educational field, even crises of education and society. This essay is based on theoretical studies and from it you risk making proposals from the potential to mobilize people to get involved and act to seek changes. We talk about the role of the State front of his duties and shows the contradictions of this, when one side takes education as a duty and the other, favors private institutions of higher education as well as other companies in the economic sector to the detriment of public education.
\end{abstract}

Keywords: Public school education. Commodification of education. 


\section{Referências}

ARROYO, Miguel Gonzaléz. Oficio de mestre: imagens e auto-imagens. Petrópolis, RJ: Vozes, 2000.

AZEVEDO, Fernando et al. Manifesto dos pioneiros da educação nova. [19--] Disponível em: <http://www.pedagogiaemfoco.pro.br/heb07a. htm >. Acesso em: 12 jan. 2010.

BERTOLIN, Júlio Cesar Godoy. A mercantilização da educação superior: uma trajetória do bem público a serviço comercial. Educação \& Realidade, Porto Alegre, v. 34, n. 3, p. 191- 211, set./dez. 2009.

BOURDIEU, Pierre. O poder simbólico: memória e sociedade. Tradução de Fernando Tomaz. Lisboa: Difel; Rio de Janeiro: Bertrand Brasil, 1989.

CECCON, Cláudius Miguel; OLIVEIRA, Darcy Rosika de. A vida na escola e a escola da vida. 31. ed. Petrópolis, RJ: Vozes, 1996.

FÁVERO, Osmar (Org.). Democracia e educação em Florestan Fernandes. Campinas, SP: Autores Associados; Niterói, Rio de Janeiro: Ed UFF, 2005.

FREIRE, Paulo. Pedagogia da autonomia. 2. ed. São Paulo: Paz e Terra, 1996.

GRAMSCI, Antônio. Os intelectuais e a organização da cultura. Tradução de Nelson Coutinho. Rio de Janeiro: Civilização Braseira, 1982.

LAVAL, Chistian. A escola não é uma empresa: o neo-liberalismo em ataque ao ensino público. Tradução de Maria Luiza M. de Carvalho e Silva. Londrina, PR: Planta, 2004.

MANACORDA, Mario Aliguiero. Marx e a pedagogia moderna. Tradução de Newton Ramos-de-Oliveira. São Paulo: Cortez, 1991.

MÉSZÁROS, István. A educação para além do capital. Tradução de Isa Tavares. São Paulo: Boitempo, 2005.

PALUDO, Conceição. Educação popular em busca de alternativas: uma leitura desde o campo democrático popular. Porto Alegre: Tomo, 2001.

PEREIRA, Vanilda Paiva. Educação popular e educação de adultos: contribuição à história da educação brasileira. São Paulo: Loyola, 1973.

PINTO, João Bosco Guedes. Reflexões sobre as estratégias educativas do Estado e a prática da educação popular. In: PAIVA, Vanilda (Org.). Perspectivas e dilemas da educação popular. 2. ed. Rio de Janeiro: Graal, 1986.

RIBEIRO, Jorge Alberto Rosa. Trabalho e educação: há razões para um novo diálogo? In: SIMIONATO, Margareth Fadanelli (Org.). Percursos investigativos em trabalho, educação e formação profissional. Novo Hamburgo, RS: FEEVALE, 2009. p. 8-25. Disponível em: < http://www.feevale. $\mathrm{br} /$ hotsite $/$ default. asp?intMenu $=3 \mathcal{E}$ intIdHotSite $=26 \&$ intIdSecao $=168$ $0 \mathcal{E}$ intIdConteudo $=25330 \mathcal{E}$ intIdPai $=25330>$. Acesso em: 12 maio 2011 . 
SADER, Emir. Prefácio. Revista Espaço Acadêmico, n. 51, ago. 2005. Disponível em: <http://www.espacoacademico.com.br/051/51liv_meszaros.htm >. Acesso em: 13 maio 2011.

SANTOS, Milton. Por uma outra globalização: do pensamento único à consciência universal. 7. ed. Rio de Janeiro: Record, 2001.

SAVIANI, Dermeval. Escola e democracia. 41. ed. São Paulo: Autores Associados, 2009.

SHIROMA, Oneida Oto. Profissionalização e gerencialismo na educação. [2003] Disponível em: < http://www.gepeto.ced.ufsc.br/arquivos/1profi ssionalizacaoegerencialismo.pdf > . Acesso em: 13 maio 2011.

STRECK, Danilo. Cidadania e financiamento da educação: onde ancorar o discurso do financiamento. In: GONSALVES, Elisa Pereira (Org.). Educação e grupos populares: temas (re)correntes. Campinas, SP: Alínea, 2002.

UNICEF. Educação no Brasil melhora, mas desigualdades ainda criam barreiras. [2010] Disponível em: < http://www.unicef.org/brazil/pt/ media_14931.htm >. Acesso em: 12 jan. 2010.

Artigo submetido em 17/05/2012 e aceito para publicação em 18/05/2012. 